\title{
Phantom limb pain: a review of pharmacological management
}

\author{
Neil Hall and Sam Eldabe
}

British Journal of Pain

2018, Vol 12(4) 202-207

(C) The British Pain Society 2017

Article reuse guidelines:

sagepub.com/journals-permissions

DOI: 10.1177/2049463717747307

journals.sagepub.com/home/bjp

@SAGE

\begin{abstract}
Introduction: Phantom limb pain (PLP) is a complex condition resulting in pain in the missing limb affecting $60-80 \%$ amputees. Increasing number of patients are undergoing amputations. Approximately 1 per every 1000 people in the United Kingdom is an amputee. Incidence of PLP can be as high as $80 \%$ following amputation. PLP can be severe and difficult to treat. A range of pharmacological interventions exist yet little is known about them in respect to PLP. This article will address the effectiveness of both single pharmacological, therapy as well as drug combination therapy.

Methods: We reviewed all literature looking at the evidence for the efficacy of both single and combined pharmacological therapy in the management of phantom limb pain. Not all commonly prescribed analgesic agents have been studied in the use of PLP and in these cases, the evidence of their efficacy in neuropathic pain was reviewed

Conclusion: It is difficult to draw definitive conclusions on the pharmacological management of PLP based on current available evidence. Most trials involved small cohorts and were not specific to the PLP. The trials which looked specifically at the PLP population gave conflicting results. Only the $\mathrm{N}$-methylD-aspartate (NMDA) receptor antagonist class demonstrated consistent positive results. Most notably ketamine did produce a reduction in pressure pain thresholds and pain windup associated with PLP, although the numbers in these studies remain small. This benefit was not demonstrated across all NMDA receptor antagonists. Combination therapy has demonstrated effectiveness in previous studies for neuropathic pain but this has never been tested specifically against a PLP cohort. Therefore, combination treatment of agents with proven efficacy in PLP such as opioid and gabapentin deserves a closer examination in a controlled study against a placebo as well as single drug therapy
\end{abstract}

\section{Keywords}

Phantom Limb, chronic pain, pain, intractable, postoperative

\section{Introduction}

Phantom limb pain (PLP) is a complex condition resulting in pain in the missing limb. It affects $60-80 \%$ amputees'. ${ }^{1}$ Increasing number of patients are undergoing amputations. ${ }^{2}$ The prevalence rate for amputation within the United Kingdom is 26.3 per $100,000 .{ }^{3}$ More than half are due to peripheral vascular disease (PVD) or diabeties. ${ }^{2}$ The incidence related to PVD alone is estimated up to 50 per 100,000 and this number is forecast to increase be $50 \%$ over the next 15 years secondary to an ageing population. ${ }^{4}$ PLP reduces quality of life $\mathrm{e}^{5}$ and has a big impact on society with only $43 \%$ patients returning to work following amputation. ${ }^{6}$
Post amputation phenomenon can consist of three elements: ${ }^{5}$

1. PLP: painful sensations referred to the absent limb

The James Cook University Hospital, Middlesbrough, UK

\section{Corresponding author:}

Neil Hall, The James Cook University Hospital, Marton Road,

Middlesbrough TS4 3BW, UK.

Email: neilhalladoctors.org.uk 
2. Phantom limb sensation: any sensation in the absent limb, except pain;

3. Stump pain: pain localized in the stump.

Incidence of PLP can be as high as $80 \%$ following amputation. ${ }^{7,8}$ This estimate has risen in recent times from the initial estimate of $2-4 \%$. Risk factors include female sex ${ }^{9,10}$ pre-amputation pain ${ }^{11}$ and depression. ${ }^{1}$ Over recent years more has been understood of the changes that develop in the central and peripheral nervous system.

Initial transection of the peripheral nerves brings about an increased release of histamine, bradykinin and prostaglandins. Sensitivity of the nociceptors to these chemicals increases leading to an increased firing of afferent neurones. There is a concurrent alteration in the sodium channel membrane potential. ${ }^{12}$ This lowered threshold potential further increases the rate of neurone impulse transmission.

Following transection of peripheral axons sprouting occurs of the ventral terminals of the large myelinated axons. This sprouting allows the sensory axons to terminate in lamina II instead of laminae III or IV. This means that the 'wrong connections' are made and sensory neurones responsible for touch might connect with the inter-neurones that normally receive input from nociceptors. ${ }^{12}$ As a result, even light touch can cause a lot of discomfort.

The increased neuronal activity leads to a central sensitization or 'Wind-up phenomenon'. ${ }^{13}$ The final factor is cortical reorganization. Once the limb has been amputated, the brain still has the old geography wired in. This leads to excessive activity in the neuromatrix due to lack of signals from the limb. ${ }^{14}$ The neuromatrix theory of pain states that the perception of painful stimuli does not result from the brain's passive registration of tissue trauma, but from its active generation of subjective experiences through a network of neurones known as the neuromatrix. ${ }^{15}$

PLP can be severe and difficult to treat. A range of pharmacological interventions exist; yet little is known about them in respect to PLP. This article will address the effectiveness of both single pharmacological therapy and drug combination therapy.

\section{Methods}

The literature was sourced from Pubmed, Embase and Cochrane central register of controlled trials (CENTRAL) up to February 2017. Search for a wide range of classes' of medications was conducted against PLP.

Pharmacological agents searched included analgesics, anticonvulsants, antidepressants, NSAID, SSRIs, opioids, tramadol, $\mathrm{N}$-methyl-D-aspartate (NMDA) receptor antagonists given either in single or combination. Primary interventions were not included. Levels of evidence used in this review are as follows:

- Level 1: meta-analysis or systemic reviews

- Level 2: one or more well-powered randomized controlled trials

- Level 3: retrospective studies. open-label trials, pilot studies

- Level 4: anecdotes, case reports, clinical experience and so on.

All studies contained human subjects only. The primary outcome measure was change in pain intensity pre and post treatment on any recognized scale. Secondary outcomes included withdrawals from studies, side effect profile, patient satisfaction, function, mood, sleep, and quality of life.

\section{Single pharmacological therapy}

\section{Tricyclic antidepressant}

The most commonly used medications for the treatment of PLP are tricyclic antidepressant (TCA). Their analgesic effect may be related to the SSRI (selective serotonin-norepinephrine uptake inhibition). ${ }^{16}$

Robinson et al. ${ }^{17}$ examined the effect of the TCA amitriptyline in a randomized controlled study. The effect of amitriptyline versus an active placebo was measured over a 6 week period in a total of 39 participants. All participants had amputation-related pain. The primary outcome measure was patient-reported average pain intensity. Amitriptyline was started at $10 \mathrm{mg}$ per day and increased to a maximum of $125 \mathrm{mg}$ per day. There was no difference between the two groups. As a result the conclusions did not support the use of amitriptyline in the treatment of post amputation pain.

The use of TCA's in PLP is not supported by the evidence to date. Certainly, the level of side effects experienced by patients on this medication during the Robinson et al. ${ }^{17}$ study remained high and must be considered in its use.

\section{Serotonin-norepinephrine reuptake inhibitor}

Venlafaxine is an SNRI (serotonin-norepinephrine reuptake inhibitor). It is important to note that venlafaxine is not recommended to date under the NICE or the Scottish SIGN guidelines as an option for neuropathic pain in non-specialist settings. The reuptake effects are dose dependent. At low doses $(<150 \mathrm{mg} /$ day), it acts only on serotonergic transmission. At moderate doses $(>150 \mathrm{mg} /$ day $)$, it acts on serotonergic and 
noradrenergic systems, whereas at high doses $(>300 \mathrm{mg} /$ day), it also affects dopaminergic neurotransmission. ${ }^{18}$

No studies measuring the effectiveness any SNRI's in relation to PLP could be found. It is worth noting a large multicentre, double-blind, randomized, placebocontrolled study examining the use of venlafaxine in painful diabetic neuropathy found a low side effect profile. ${ }^{19}$ This was not the case with duloxetine where most duloxetine users in the trial demonstrated at least one side effect. ${ }^{20}$

\section{Anticonvulsants}

Gabapentin is an anticonvulsant commonly used to treat pain since the 1960s. The action of gabapentin is complex and may inhibit the release of excitatory neurotransmitters and reduce glutamate availability at NMDA and non-NMDA receptors. ${ }^{21}$ However, its main action in respect to neuropathic pain is believed to be via the binding to the $\alpha$-2-delta subunit of voltage-dependant calcium channels. This leads to reduction of the influx of calcium into neurones. ${ }^{22}$

A randomized, double-blind, placebo-controlled, crossover study examined the effect of gabapentin alone in PLP. Nineteen patients were randomized. The primary outcome measure was visual analogue scale (VAS) pain intensity difference (PID) compared with baseline at the end of each treatment. Daily doses of up to $2400 \mathrm{mg}$ were used. PID was significantly greater in the gabapentin group $(3.2 \pm 2.1$ vs $1.6 \pm 0.7, P=.03)$, with no effect on activities of daily living. The authors concluded after 6 weeks that gabapentin monotherapy was better than placebo in relieving post amputation PLP. ${ }^{23}$

Smith et al. examined 24 patients in a double-blind crossover trial. Inclusion criteria consisted of lower limb amputation more than 6 months prior and an average pain of at least 3 on a $0-10$ numerical rating scale (NRS). The primary outcome measure was NRS. The effect of gabapentin up to a higher maximum dose of $3600 \mathrm{mg}$ was compared against placebo over a 5 -week period. More than half of the participants reported improved functioning, satisfaction and global improvement, although no discernible difference in the primary measure (NRS) between groups. This was compared to about one-fifth who reported a meaningful decrease in pain during the placebo phase. ${ }^{24}$

The above gabapentin studies involved only small numbers of subjects. It is therefore difficult to draw any meaningful conclusions regarding the specific clinical effectiveness of the drug in PLP.

Nikolajsen et al. also examined the effects of early gabapentin post amputation against placebo. Fortyone patients were included and treatment was started on the first postoperative day and continued for
30 days. A maximum dose of gabapentin $2400 \mathrm{mg}$ was used. The authors concluded that there was no reduction in incidence or intensity of post amputation pain between the two groups..$^{25}$

Topiramate is a gamma-aminobutyric acid (GABA) agonist, sodium channel blocker and kainate antagonist. A pilot prospective, double-blind, randomized, placebo-controlled study examined the effect of topiramate on four PLP patients. A statistically significant reduction of $70-80 \%$ VAS was observed between daily doses of $25-800 \mathrm{mg} .{ }^{26}$ Although well tolerated, side effects including acute myopia have been reported in the first 4 weeks of topiramate treatment. ${ }^{27}$ It is hard to draw any conclusion however from such a small cohort of patients, although the drug potentially warrants a more definitive study. The use of pregabalin in PLP has not been examined to date.

\section{Calcitonin}

The outcomes of calcitonin therapy in PLP have produced mixed results. The use of calcitonin (200 IE) was examined in chronic PLP against and in combination with ketamine $(0.4 \mathrm{mg} / \mathrm{kg})$ infusion in a 20 participant randomized, double-blind trial. Intensity of phantom pain (VAS) was recorded before, during, at the end and $48 \mathrm{~h}$ after each infusion. Ketamine, but not calcitonin, reduced PLP. The authors concluded that ketamine but not calcitonin affects central sensitization occurring in PLP. ${ }^{28}$

A double-blind crossover comparison of Calcitonin 200 IU infusion against a placebo recruited 21 patients who had undergone major amputations and developed severe PLP up to 7 days postoperatively. Calcitonin infusion reduced pain levels on a numeric analogue scale (NAS) from a median of 7 to 4 . Placebo had no effect of pain scores. There was evidence of some longer lasting effects. One week after treatment, 19 patients $(90 \%)$ had pain relief of more than $50 \%, 16(76 \%)$ were completely pain free and 15 (71\%) never experienced PLP again. One year later 8 out of the 13 surviving patients $(62 \%)$ still had more than $75 \%$ PLP relief. After 2 years PLP exceeded 3 on VAS in 5 individuals (42\%), and the remaining 12 patients presented the same PLP as after 1 year. The authors therefore concluded that calcitonin is effective for the prophylaxis of PLP in the early postoperative period. ${ }^{29}$

\section{NMDA receptor antagonists}

Hyperactivity of NMDA receptors may be one of the factors in the maintenance of persistent stump and PLP. ${ }^{30}$ Nikolajsen et al. examined the effect of ketamine on PLP. They infused ketamine (bolus at $0.1 \mathrm{mg} /$ 
$\mathrm{kg} / 5 \mathrm{~min}$ followed by an infusion of $7 \mu \mathrm{g} / \mathrm{kg} / \mathrm{min}$ ) administered to 11 patients with established PLP. Ketamine resulted in a reduction in pain in all 11 patients (VAS and McGill Pain Questionnaire). Ketamine increased pressure pain thresholds significantly. Wind-up like pain was also reduced. The authors therefore concluded that NMDA receptor antagonists might be effective in stump and PLP. ${ }^{30}$ This was further re-enforced by Eichenberger et al. ${ }^{28}$ as described above that ketamine potentially affects central sensitization occurring in PLP.

This would warrant further study with a larger cohort to ascertain the effect of ketamine in PLP. Ketamine has a substantial side effect profile. This has been known since 1960s when it was introduced in Anaesthesia practice. Side effects include cystitis, hallucinations and cardiovascular effects.

Dextromethorphan has been shown to alleviate pain in both human and animal models. A pilot double-blind crossover trial of three patients with cancer amputation pain showed oral dextromethorphan $120-270 \mathrm{mg}$ daily effectively reduced PLP. Pain recurred in one patient a month after stopping treatment. ${ }^{32}$ Again an adequately powered clinical trial is required to explore this further since the drug possibly offers a less severe side effect profile in comparison to ketamine.

Wiech et al. ${ }^{33}$ conducted a placebo-controlled randomized crossover trial of Memantine ( $30 \mathrm{mg}$ daily) in eight PLP patients. The drug had no effect on chronic PLP. This was further demonstrated by a randomized, double-blind controlled trial with 19 patients undertaken by Schley et al. Memantine (20-30 mg daily) was used against placebo and demonstrated a reduction in PLP intensity at 1 month, 6 months but not at 12 months. As a result, the authors concluded that no long-term effect on established PLP was evident. ${ }^{34}$

\section{Opioids}

Randomized control trials have demonstrated a benefit of opioids in PLP. It is hypothesized that they may also reduce cortical reorganization. ${ }^{35}$.

Huse et al. examined the efficacy of morphine sulphate orally (MST) against placebo in a doubleblinded crossover design in 12 patients with PLP. A dose of $70-300 \mathrm{mg} /$ day showed a short-term clinically relevant response to MST (pain reduction of more than $50 \%$ on VAS) was evident in $42 \%$, a partial response (pain reduction of $25-50 \%$ ) in $8 \%$ of the patients. Interestingly, neuromagnetic source imaging of three patients showed evidence for reduced cortical reorganization with MST. The authors therefore concluded that opioids show promise in reducing PLP and potentially influence cortical reorganization. ${ }^{31}$ It must be noted opioid-induced hyperalgesia is a risk at higher doses. Furthermore, the recommendation from Public Health England states any dose above $120 \mathrm{mg}$ /day oral morphine equivalent risk of harm increases substantially with no increased benefit. ${ }^{36}$

Wu et al. measured the effects of intravenous lignocaine and morphine administered to post amputation stump and PLP patients (31) over three consecutive days. They infused morphine $(0.05 \mathrm{mg} / \mathrm{kg}$ bolus + $0.2 \mathrm{mg} / \mathrm{kg}$ infusion over $40 \mathrm{~min})$, lidocaine $(1 \mathrm{mg} / \mathrm{kg}$ bolus $+4 \mathrm{mg} / \mathrm{kg}$ infusion) and the active placebo, diphenhydramine (10 mg bolus $+40 \mathrm{mg}$ infusion). Compared with the placebo, morphine reduced both stump and phantom pains significantly $(P<0.01)$. In comparison lidocaine decreased stump $(\mathrm{P}<0.01)$, but not phantom pain. Stump pain was reduced both by morphine and lidocaine, while phantom pain was reduced only by morphine. The conclusion enhanced the theory that stump pain and PLP have a different underlying pathophysiology. This was however only a short-term study with pain scores only measured 30 minutes post infusion. ${ }^{37}$

A double-blind, randomized, placebo-controlled, crossover study in adult patients with post amputation pain of 6 months or longer and greater than 3 on a 0-10 numeric pain rating scale was conducted by Wu et al. They examined three treatment periods (morphine, mexiletine or placebo) included a 1-week drugfree interval followed by 4 -week titration, 2 -week maintenance and 2-week drug-taper phases. The primary outcome measure was change in average pain intensity from the drug-free baseline to the last week of maintenance. Morphine, but not mexiletine, resulted in a decrease in intensity of post amputation pain but were associated with a higher rate of side effects and no improvement in self-reported levels of overall functional activity and pain-related interference in daily activities. $^{38}$

Long-term safety remains an issue with chronic opioid usage. The debate on the long-term opioid usage in chronic pain is out of the scope of this article.

\section{Conclusion}

It is difficult to draw definitive confusions on the pharmacological management of PLP based on current available evidence. Most trials involved small cohorts and gave conflicting results. Mixed results arguably reinforces our understanding that the management of PLP is complex and the answers do not lie in pharmacology alone.

Only the NMDA receptor antagonist class demonstrated consistent positive results. Most notably ketamine did produce a reduction in pressure pain thresholds and pain windup associated with PLP, 
although the numbers in these studies remain small. Timing may be important with this class of agents. Memantine given early postoperatively following amputation has resulted in a decreased PLP, although this effect was not maintained long term. ${ }^{37}$ The well recorded side effects of long-term ketamine including the potential for ketamine cystitis may be an obstacle to long-term use. ${ }^{39}$

When considering where future studies for the effectiveness of pharmacological agents in PLP should lie, evidence can be drawn from other neuropathic pain conditions. TCAs such as amitriptyline have in the past been a mainstay in the treatment of neuropathic pain. ${ }^{40}$ However, alternative agents such as Venlafaxine are potentially demonstrating the same efficacy need to be investigated further. ${ }^{18}$ They may offer a solution to PLP with the advantage of a lower side effect profile. ${ }^{19}$ SSRI and SNRI agents such as Duloxetine have been shown to be effective in the treatment of diabetic neuropathy pain and may have a place in the management of PLP. ${ }^{20}$

Pregabalin has proven effectiveness in various causes of neuropathies. ${ }^{41}$ Its efficacy in PLP remains unknown. There has been increasing use of this drug over the last few years and therefore increasing understanding of its side effect profile with regard to a potential trial.

Combination therapy was shown to be effective in previous studies for neuropathic pain. ${ }^{42-44}$ Therefore, combination treatment such as opioid and gabapentin for PLP deserves a closer examination in a controlled study against a placebo as well as single drug therapy.

\section{Conflict of interest}

The authors declare that there is no conflict of interest.

\section{Funding}

This research received no specific grant from any funding agency in the public, commercial or not-for-profit sectors.

\section{References}

1. Ephraim PL, Wegener ST, MacKenzie EJ, et al. Phantom pain, residual limb pain, and back pain in amputees: results of a national survey. Arch Phys Med Rehabil 2005; 86(10): 1910-1919.

2. Norgren L, Hiatt WR, Dormandy JA, et al. Inter-Society Consensus for the Management of Peripheral Arterial Disease (TASC II). F Vasc Surg 2007; 45: S5-S67.

3. Ahmad N, Thomas GN, Gil P, et al. Lower limb amputation in England: prevalence, regional variation and relationship with revascularisation, deprivation and risk factors. A retrospective review of hospital data. $\mathcal{F} R$ Soc Med 2014; 107(12): 483-489.

4. Ziegler-Graham K, MacKenzie EJ, Ephraim PL, et al. Estimating the prevalence of limb loss in the United States: 2005 to 2050. Arch Phys Med Rehabil 2008; 89(3): 422-429
5. Nikolajsen $\mathrm{L}$ and Jensen TS. Phantom limb pain. $\mathrm{Br} \mathcal{F}$ Anesth 2001; 87(1): 107-16.

6. Whyte AS and Carroll LJ. A preliminary examination of the relationship between employment, pain and disability in an amputee population. Disabil Rehabil 2002; 24(9): 462-470.

7. Richardson C, Glenn S, Nurmikko T, et al. Incidence of phantom phenomena including phantom limb pain 6 months after major lower limb amputation in patients with peripheral vascular disease. Clin F Pain 2006; 22(4): 353-358.

8. Reiber GE, Mcfarland LV, Hubbard S, et al. Servicemembers and veterans with major traumatic limb loss from Vietnam war and OIF/OEF conflicts: survey methods, participants, and summary findings. $\mathcal{F}$ Rehabil Res Dev 2010; 47(4): 275-297.

9. Bosmans JC, Geertzen JHB, Post WJ, et al. Factors associated with phantom limb pain: a 31/2-year prospective study. Clinical Rehabilitation 2010; 24(5): 444-453.

10. Davidson JH, Khor KE and Jones LE. A cross-sectional study of post-amputation pain in upper and lower limb amputees, experience of a tertiary referral amputee clinic. Disabil Rehabil 2010; 32(22): 1855-1862.

11. Desmond DM and Maclachlan M. Prevalence and characteristics of phantom limb pain and residual limb pain in the long term after upper limb amputation. Int $\mathcal{F}$ Rehabil Res 2010; 33(3): 279-282.

12. Dickinson BD, Head CA, Gitlow S, et al. Maldynia: pathophysiology and management of neuropathic and maladaptive pain - a report of the AMA council on science and public health. Pain Med 2010; 11(11): 16351653.

13. Baron R. Mechanisms of disease: neuropathic pain - a clinical perspective. Nat Clin Pract Neurol 2006; 2(2): 95-106

14. Ramachandran VS, Brang D and McGeoch PD. Dynamic reorganization of referred sensations by movements of phantom limbs. NeuroReport 2010; 21(10): 727-730.

15. Chapman C. Neuromatrix theory. F Pain 1996; 5(2), pp.139-142.

16. Verdu B, Decosterd I, Buclin T, et al. Antidepressants for the treatment of chronic pain. Drugs 2008; 68(18): 2611-2632.

17. Robinson L, Czerniecki J, Ehde D, et al. Trial of amitriptyline for relief of pain in amputees: results of a randomized controlled study. Arch Phys Med Rehabil 2004; 85(1): 1-6.

18. Redrobe JP, Bourin M, Colombel MC, et al. Dosedependent noradrenergic and serotonergic properties of venlafaxine in animal models indicative of antidepressant activity. Psychopharmacology 1998; 138(1): $1-8$.

19. Rowbotham MC, Goli V, Junz NR, et al. Venlafaxine extended release in the treatment of painful diabetic neuropathy: a double-blind, placebo-controlled study. Pain 2004; 100: 697-706.

20. Lunn MP, Hughes RA and Wiffen PJ. Duloxetine for treating painful neuropathy, chronic pain or fibromyalgia. Cochrane Database Syst Rev 2014; 1: CD007115. 
21. Shimoyama $\mathrm{M}$, Shimoyama $\mathrm{N}$ and Hori Y. Gabapentin affects glutamatergic excitatory neurotransmission in the rat dorsal horn. Pain 2000; 85: 405-414.

22. Jensen TS, Madsen CS and Finnerup NB. Pharmacology and treatment of neuropathic pains. Curr Opin Neurol 2009; 22(5): 467-474.

23. Bone M, Critchley P and Buggy D. Gabapentin in postamputation phantom limb pain: a randomized, doubleblind, placebo-controlled, cross-over study. Reg Anesth Pain Med 2002; 27(5): 481-486.

24. Smith DG, Ehde DM, Hanley MA, et al. Efficacy of gabapentin in treating chronic phantom limb and residual limb pain. F Rehabil Res Dev 2005; 42(5): 645-654.

25. Nikolajsen L, Finnerup NB, Kramp S, et al. A randomized study of the effects of gabapentin on postamputation pain. Anesthesiology 2006; 105(5): 1008-1015

26. Harden RN, Houle TT, Remble TA, et al. Topiramate for phantom limb pain: a time-series analysis. Pain Med 2005; 6(5): 375-378.

27. Murray L (ed.). Physicians' desk reference. Montvale, NJ: Thompson PDR, 2004.

28. Eichenberger U, Neff F, Sveticic G, et al. Chronic phantom limb pain: the effects of calcitonin, ketamine, and their combination on pain and sensory thresholds. Anesth Analg 2008; 106(4): 1265-1273

29. Jaeger $\mathrm{H}$ and Maier C. Calcitonin in phantom limb pain: a double-blind study. Pain 1992; 48: 21-27

30. Nikolajsen L, Hansen CL, Nielsen J, et al. The effect of ketamine on phantom pain: a central neuropathic disorder maintained by peripheral input. Pain 1996; 67(1): 69-77.

31. Huse E, Larbig W, Flor H, et al. The effect of opioids on phantom limb pain and cortical reorganization. Pain 2001; 90(1-2): 47-55.

32. Ben Abraham R, Marouani N, Kollender Y, et al. Dextromethorphan for phantom pain attenuation in cancer amputees: a double-blind crossover trial involving three patients. Clin F Pain 2002; 18(5): 282-285.

33. Wiech K, Kiefer RT, Töpfner S, et al. A placebo-controlled randomized crossover trial of the N-methylD-aspartic acid receptor antagonist, memantine, in patients with chronic phantom limb pain. Anesth Analg 2004; 98(2): 408-413.
34. Schley M, Topfner S, Wiech $\mathrm{K}$, et al. Continuous brachial plexus blockade in combination with the NMDA receptor antagonist memantine prevents phantom pain in acute traumatic upper limb amputees. Eur $\mathcal{f}$ Pain 2007; 11(3): 299-308.

35. Weeks SR, Anderson-Barnes VC and Tsao JW. Phantom limb pain: theories and therapies. Neurologist 2010 16(5): 277-86

36. The Royal College of Anaesthetists. Opioids aware: a resource for patients and healthcare professionals to support prescribing of opioid medicines for pain, 2017, http://www.fpm.ac.uk/faculty-of-pain-medicine/opioidsaware

37. Wu C, Tella P, Staats P, et al. Analgesic effects of intravenous lidocaine and morphine on postamputation pain: a randomized double-blind, active placebocontrolled, crossover trial. Anesthesiology 2002; 96(2): 841-848.

38. Wu C, Agarwal S, Tella P, et al. Morphine versus mexiletine for treatment of postamputation pain: a randomized, placebo-controlled, crossover trial. Anesthesiology 2008; 109(2): 289-296.

39. Sassano-Higgins S, Baron D, Juarez G, et al. A review of ketamine abuse and diversion. Depress Anxiety 2016; 33(8): 718-727.

40. Moore R, Derry S, Aldington D, et al. Amitriptyline for neuropathic pain in adults. Cochrane Database Syst Rev 2015; 7: CD008242.

41. Moore RA, Straube S, Wiffen PJ, et al. Pregabalin for acute and chronic pain in adults. Cochrane Database Syst Rev 2009; 3: CD007076.

42. Chaparro LE, Wiffen PJ, Moore RA, et al. Combination pharmacotherapy for the treatment of neuropathic pain in adults. Cochrane Database Syst Rev 2012; 7: CD008943.

43. Hanna M, O'Brien C and Wilson MC. Prolongedrelease oxycodone enhances the effects of existing gabapentin therapy in painful diabetic neuropathy patients. Eur f Pain 2008; 12: 804-813.

44. Gilron I, Bailey JM, Tu D, et al. Morphine, gabapentin, or their combination for neuropathic pain. $N$ Engl $\mathcal{F ~ M e d ~}$ 2005; 352(13): 1324-1334. 